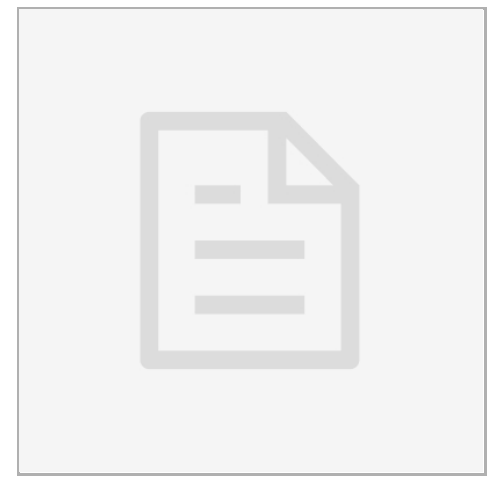

APR 29, 2020

\section{(3) Microbiome Assay with 96WP Updated April 2020}

Priota Islam ${ }^{1}$

${ }^{1}$ Imperial College London

Behavioural Genomics

Priota Islam

Imperial College London

\section{open ठaccess}

\section{DOI:}

dx.doi.org/10.17504/protocol s.io.bfrqjm $5 \mathrm{w}$

Protocol Citation: Priota Islam 2020. Microbiome Assay with 96WP Updated April 2020. protocols.io

https://dx.doi.org/10.17504/p rotocols. io. bfrajm5w

License: This is an open access protocol distributed under the terms of the Creative Commons Attribution License, which permits unrestricted use, distribution, and reproduction in any medium, provided the original author and source are credited

Protocol status: Working We use this protocol and it's working

Created: Apr 29, 2020

Last Modified: Apr 29, 2020

\section{PROTOCOL integer ID:} 36368

\section{-10 days}

1 Pick 10 L4s onto $10 \times 90 \mathrm{~mm}$ OP50 seeded platese.gon Monday (10 L4 per plate so total 100L4s) 


\section{-6 days}

2 At 2pm on day of bleaching (eg Friday) follow the protocol Bleach synchronization of C elegans

3 Keep the tube with bleached N2s on a rotator at 20C incubator until refeed (make sure not to exceed 5 days as the worm behaviour is not consistent post this time frame)

\section{-3 days}

4 If tracking is intended to be performed on the following Thursday, then refeed the arrested L1s onto 4 OP50 seeded $150 \mathrm{~mm}$ plates on the Monday $(+72 \mathrm{hrs}$ post bleaching, at $2 \mathrm{pm}$ following the protocol Bleach synchronization of $\mathrm{C}$ elegans

5 Store the refed L1 plates at 20C incubator

\section{-2 days}

6 At least 2days prior to tracking day (e.g. Tuesday if tracking is planned on Thursday) make about $250 \mathrm{ml}$ no peptone NGM

7 Dispense 200ul of agar into each well of the 96WP using the integra viafill following the protocol Dispensing agar into multi well plates

8 Let the agar dry and store the plates at 4C (lid side down) until used (plates can be stored for up to a week)-Note: 
9 Measure the weight of the plates with lids on and record average plate weight on day of pouring

10 Grow an overnight culture of the bacterial strain from the (shuffled) 96WP library stock plates, 2days prior to tracking (eg on a Tuesday afternoon if tracking is to be intended on Thursday) following the protocol Growing overnight bacterial culture in 96WP.

11 Cover the plates with breathable seals and shake at 180-200rpm in a shaking incubator

12 Separately inoculate OP50 and incubate at 37C overnight in a shaking incubator at $200 \mathrm{rpm}$

\section{-1 day}

13 Take the bacterial cultures out of the incubators in the morning, and store at $4 \mathrm{C}$ until used for seeding later that day

14 Take agar-filled 96WPs out of the cold room and dry under in the drying cabinet for about 2-3hrs (Measure the weight of 3 plates before drying without the lid)

15 After drying measure the weight of the 3 plates again. Ensure that the plates lose between 3-5\% of their original weight following drying.

16 Seed the dried plates with the bacterial culture grown the night before using the ViaFlo 
17 Turn the ViaFlo ON (Make sure to book it beforehand)

18 Edit the protocol SAUL to have the mixing stage consisting of 15 cycles to initially mix the bacterial cultures and to resuspend each strain

19 Load the tips (long 12ul tips), Adjust the $Z$ height to the one that worked best in the test runs (See lab notes)

20 Mix the bacterial plate using the ViaFlo

21 Change the tips

22 Edit protocol SAUL again to have mixing stage be of 1 cycle when actually seeding plates

23 Run the protocol- To dispense 10ul volume in each well

24 Change tips every time a new plate is seeded 
25 After all the plates are seeded dry them under the hood for another $1 \mathrm{hr}$

26 After drying put the plates in a closed box upside down in the cold room (4C)

\section{Day 0: Tracking day}

27 On the day of tracking prepare the worms following the protocol Preparing worms for the COPAS (wormsorter)

28 Dispense the worms using the COPAS following the protocol Using the worm sorter (COPAS)

29 Dry the plates for 30 minutes under the hood

30 After drying, place the plates under the Hydra rig, leave for a further $30 \mathrm{mins}$ to acclimatize, and then record for $15 \mathrm{mins}$, following the protocol Tracking on the Hydra rigs

31 Record with the lids on and lid side facing up inside the rig. Makesure to wipe the lids with lint-free tissues before placing them under the rig. Also use the script that involves using blue light in the recording

32 Record each plate at four time points: $1 \mathrm{hr}, 3 \mathrm{hrs}, 5 \mathrm{hrs}$, and $23.5 \mathrm{hrs}$ (next day). Between $1 \mathrm{hr}, 3 \mathrm{hr} \&$ $5 \mathrm{hr}$ the plates are kept in the cave outside the rigs 
33 Store the plates in $20 \mathrm{C}$ incubator overnight between tracking $5 \mathrm{hrs}$ and $23.5 \mathrm{hrs}$ timepoint

34 Discard the plates in the biological waste bins post tracking 